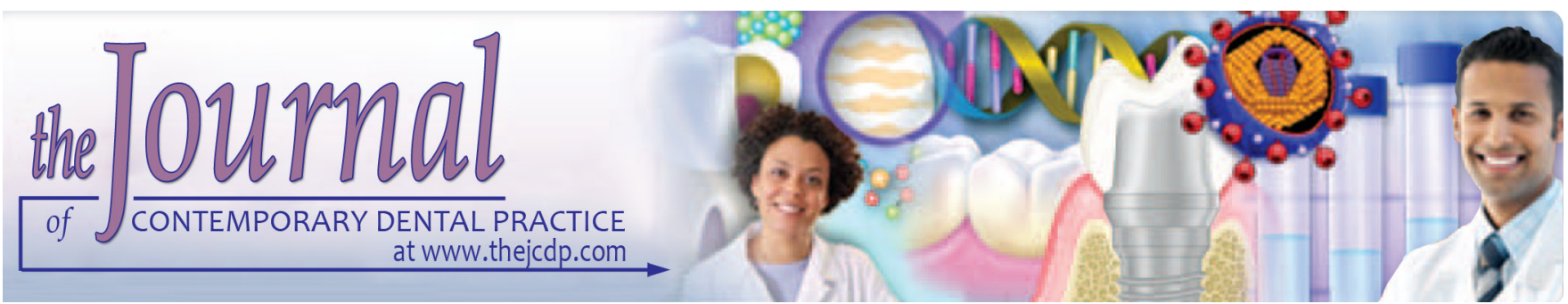

\title{
Smear Layer Removing Ability of Root Canal Irrigation Solutions: A Review
}

\author{
1Zahed Mohammadi, ${ }^{2}$ Sousan Shalavi, ${ }^{3}$ Shapour Yaripour, ${ }^{4}$ Jun-Ichiro Kinoshita, ${ }^{5}$ Atsufumi Manabe, \\ ${ }^{6}$ Mikihiro Kobayashi, ${ }^{7}$ Luciano Giardino, ${ }^{8}$ Flavio Palazzi, ${ }^{9}$ Farid Sharifi, ${ }^{10} \mathrm{Hamid}$ Jafarzadeh
}

\section{ABSTRACT}

Aim: The purpose of this review is to address the smear layer removing the ability of root different canal irrigants including ethylenediaminetetraacetic acid (EDTA), a mixture of tetracycline, acid and detergent (MTAD), tetraclean, citric acid, Q-Mix, maleic acid, and smear clear.

Background: Smear layer is a layer which is produced during instrumentation. It contains both organic and inorganic materials. It may also contain bacteria and their byproduct considering the root canal situation. This layer may prevent the penetration of the healing material introduced to the canal to the interior of the dentinal tubules. In addition, it can affect the adaptation of sealing materials to the root canal walls.

Review results: The smear layer removal ability of MTAD is superior and faster than EDTA. Tetraclean is similarly composed of an acid, an antibiotic, and a detergent. The presence of doxycycline is believed to help the smear layer removal ability of these irrigants. Antibiotics such as tetracycline had similar smear layer removal ability as even citric acid. EDTA

${ }^{1}$ Iranian Center for Endodontic Research (ICER), Research Institute of Dental Sciences, Shaheed Beheshti University of Medical Sciences, Tehran, Islamic Republic of Iran

${ }^{2}$ General Dental Practitioner, Hamedan, Islamic Republic of Iran

${ }^{3}$ Department of Oral and Maxillofacial Surgery, Faculty of Dentistry, Hamedan University of Medical Sciences, Hamedan, Islamic Republic of Iran

${ }^{4-6}$ Department of Conservative Dentistry, Showa University Dental Hospital, Tokyo, Japan

${ }^{7}$ Department of Periodontology, Endodontology, Pharmacology and Microbiology, Dental School, University of Brescia, Italy

${ }^{8}$ Department of Odontostomatological and Maxillofacial Sciences, Federico II University of Naples, Italy

${ }^{9,10}$ Dental Research Center, Mashhad University of Medical Sciences, Mashhad, Islamic Republic of Iran

Corresponding Author: Hamid Jafarzadeh, Dental Research Center, Mashhad University of Medical Sciences, Mashhad, Iran, Phone: +98-51-38829501, e-mail: hamid_365@yahoo. com; JafarzadehBH@mums.ac.ir is an amino acid with a chelating ability that sequestrates metal ions. Some believed EDTA smear layer removing ability is better than MTAD, tetraclean, SmearClear, and $20 \%$ citric acid which is controversial in case of comparison between MTAD and EDTA. Phosphoric acid is efficient enough to be comparable to EDTA in removing the smear layer. Maleic acid is an organic compound with acid etching smear layer removal. Its ability seems to be similar or even better than EDTA. Citric acid as another organic acid is believed to be used as smear removing agent. HEBP is another chelating agent that can be used in combination with $\mathrm{NaOCl}$; however, HEBP is a weak decalcifying agent compared to EDTA and hence cannot be applied as a mere final rinse. QMiX is a combination of $\mathrm{CHX}$, EDTA, and detergent and should be used at final rinse. It is believed that QMiX is as efficient as EDTA. Smear clear is a $17 \%$ EDTA solution including an anionic and cationic (cetrimide) surfactant. The ability of QMiX is similar to EDTA.

Conclusion: There are different canal irrigation solutions with various smear layer removal ability that some should be used as a mere final rinse and some should not.

Clinical significance: The usage of canal irrigation solutions depends on the clinical situation and preference of the dentists. This study provides a good guide for clinician of the field.

Keywords: Citric acid, Ethylenediaminetetraacetic acid, Irrigation, Maleic acid, Mixture of tetracycline, acid and detergent, Smear layer.

How to cite this article: Mohammadi Z, Shalavi S, Yaripour S, Kinoshita J, Manabe A, Kobayashi M, Giardino L, Palazzi F, Sharifi F, Jafarzadeh H. Smear Layer Removing Ability of Root Canal Irrigation Solutions: A Review. J Contemp Dent Pract 2019;20(3):395-402.

Source of support: Nil

Conflict of interest: None

\section{INTRODUCTION}

Apart from recent products, chelators and acids were the only decalcifying solutions used in endodontics, mostly EDTA and citric acid. However, several combinations containing characteristics thought helpful for treatment have been produced nowadays. Among these features are 
decreased surface tension and significant antimicrobial activity. The bases of these recent products are mainly composed of EDTA or citric acid. ${ }^{1}$

A smear layer is produced during the instrumentation process. Although the exact components of this layer have not been determined yet, it is believed to contain thin particles of organic elements and inorganic materials such as odontoblastic processes, pulp tissue debris, blood cells, bacteria, etc. ${ }^{2}$

At the first stages of the intervention, the organic part of the smear layer is higher due to the presence of vital pulp tissue. The smear layer may be found both on the canal wall and into some dental tubules. None of the instrumentation techniques could erase the canal debris totally. Both mechanical and manual shaping produced smear layer and debris. ${ }^{3-6}$

According to Ahlquist et al., ${ }^{7}$ rotary techniques produced more debris than manual techniques. On the other hand, in another experiment, the Quantec rotary system managed to result in cleaner canal walls than conventional manual instrumentation. ${ }^{8}$

An evaluation was performed on the occurrence of bacterial colonization in the dentinal tubules during root canal instrumentation that showed areas without the smear layer are free of Streptococcus sanguis colonization in $88 \%$ of the cases. ${ }^{9}$

To achieve fast disinfection with intracanal medicaments, smear layer should be removed and dental tubules should have their patency. ${ }^{10,11}$ Furthermore, removal of the smear layer ${ }^{12,13}$ can result in better adaptation of the obturation materials to the canal walls more.

Reports have been proposed that the removal of smear layer during apicoectomy can fail retrograde filling of the glass-ionomer. ${ }^{14}$ An investigation suggested that root canal sealer infiltration into dentinal tubules, whose smear layer was removed, was irrelevant to higher bond strengths. ${ }^{15}$ Kokkas et al. ${ }^{16}$ revealed that after smear layer degradation, sealers infiltrate at varying depths. The smear layer existence may facilitate some sealers bonding to the root canal walls. Nevertheless, Gettleman et al. ${ }^{17}$ reported no adhesive strength changes in the presence or absence of smear layer with Sealapex and Sultan sealers.

In this part, different irrigating solutions are to be reviewed and discussed.

\section{Mixture of Tetracycline, Acid and Detergent}

BioPure (Dentsply, OK, USA, Tulsa Dental, Tulsa), also known as MTAD, was presented by Torabinejad et al. in 2003. It consists of, $4.25 \%$ citric acid, $3 \%$ doxycycline, and a detergent $(0.5 \%$ Polysorbate 80$){ }^{18}$

Torabinejad et al. ${ }^{18}$ for the first time, proposed MTAD as an effective solution for smear layer removal with minimal changes in the dentinal tubules structure, especially in case of canals irrigation with $\mathrm{NaOCl}$, the subsequent rinse with MTAD. Another investigation by Torabinejad reported that although, as an intracanal irrigant, MTAD could eliminate most of the smear layer, remnants of the organic parts of the smear layer may scatter on the canal walls. ${ }^{19}$

The smear layer removing the ability of MTAD would be empowered when intracanal irrigation was conducted by diluted $\mathrm{NaOCl}$ before final rinse with MTAD. However, another investigation proposed that MTAD is unable to eliminate the smear layer. ${ }^{20}$ Tay et al. ${ }^{21}$ found that both EDTA and MTAD can create a demineralized collagen zone of matrices around the dentinal tubules and in eroded dentin, and acidic Bio Pure MTAD was more aggressive than EDTA mildly. Hydrophilic adhesive or sealers may hybridize the demineralized dentin zones. However, the outcome of hydrophobic sealers compaction against air-dried, hydrolytic degradation of incompletely infiltrated matrices, and collapsed collagen matrices remain unresolved. In an ultrastructural study, the same mentioned researcher demonstrated that the resulted demineralized dentin matrix by MTAD was thicker than EDTA. De-Deus et al. ${ }^{22}$ showed that the demineralization kinetics prompted by MTAD was significantly quicker than those prompted by a $17 \%$ EDTA.

\section{Tetraclean}

Tetraclean (Ogna Laboratori Farmaceutici, Muggiò (Mi), Italy), similar to MTAD, is a combination of an acid, an antibiotic, and a detergent. However, there are differences with MTAD such as the type of detergent (polypropylene glycol) and the concentration of the antibiotic, doxycycline $(50 \mathrm{mg} / \mathrm{mL}){ }^{23} \mathrm{In}$ a comparison made by Giardino et al. ${ }^{24}$ between the surface tension of $17 \%$ EDTA, $5.25 \% \mathrm{NaOCl}$, MTAD, Cetrexidin, Smear clear, and Tetraclean. EDTA and $\mathrm{NaOCl}$ showed the top-rated surface tensions, while Tetraclean and Cetrexidin had the lowest rates.

\section{Smear Layer Removing Ability}

Poggio et al. ${ }^{25}$ Tetraclean treatment cause higher $\mathrm{Ca}^{2+}$ release which is an evidence of significantly higher demineralizing capability than other tested irrigants.

Tetracyclines, as bacteriostatic antibiotics that cover a variety of the bacteria, are comprised of tetracycline$\mathrm{HCl}$, demeclocycline, monocycline, and doxycycline. ${ }^{18}$ This property may be an advantage as they do not lyse the bacterial cell wall and do not produce antigens like endotoxins. ${ }^{26}$

Apart from their antimicrobial action, Tetracyclines also have many special properties, such as inhibition from tissue degradation by inhibiting the mammalian 
collagenases $^{27}$ and clastic cells. ${ }^{27-29}$ It also can enhance collagen and bone formation in inflammatory diseases such as periodontitis because of its ability to block tissue collagenases which elevate in such diseases. ${ }^{26}$

The smear layer removal is one of the uses of Tetracycline during the instrumentation of canal walls. ${ }^{26,30}$ It is also used for retrograde cavities irrigation in periapical surgical procedures ${ }^{31}$ and as an intracanal medicament. ${ }^{32}$

Barkhordar et al. ${ }^{26}$ showed the efficiency of doxycycline$\mathrm{HCl}$ to eliminate the smear layer mainly in the concentration of $100 \mathrm{mg} / \mathrm{mL}$. In another investigation, tetracycline and citric acid had the same effect in removing the smear layer. ${ }^{30}$ Another study showed that irrigating the amalgam fillings and retrograde IRM with doxycycline inhibited the dye penetration significantly. ${ }^{31}$

\section{Ethylenediaminetetraacetic Acid}

Ethylenediaminetetraacetic acid (EDTA) is an amino acid with the formula of $\left(\mathrm{HO}_{2} \mathrm{CCH}_{2}\right)_{2} \mathrm{NCH}_{2} \mathrm{CH}_{2} \mathrm{~N}\left(\mathrm{CH}_{2} \mathrm{CO}_{2} \mathrm{H}\right)_{2}$ that has a chelating effect and can sequester di- and trivalent metal ions. The carboxylate and amine groups are responsible for metal binding in EDTA. EDTA construct especially powerful combinations with $\mathrm{Cu}(\mathrm{II})$, $\mathrm{Mn}(\mathrm{II})$, and $\mathrm{Co}(\mathrm{III})$, and Fe(III). EDTA is frequently synthesized using 1, 2-diaminoethane (ethylenediamine), formaldehyde (methanol), water and sodium cyanide. The resulted tetrasodium salt, which can be converted into the acidic forms through acidification process. ${ }^{33}$

EDTA is a polyamino carboxylic acid and a watersoluble, colorless solid. It is frequently used in dissolving limescale. Being chelating agent and hexadentate ligand (such as the ability to sequester metal ions like $\mathrm{Ca}^{2+}$ and $\mathrm{Fe}^{3+}$ ) has made EDTA applicable. The metal ions showed lower reactivity in the solution when binding EDTA. Disodium EDTA and calcium disodium EDTA are among a variety of the produced salts. The first proposed formulation of the EDTA was proposed by Ferdinand Munz in 1935 that was a combination of ethylenediamine and chloroacetic acid. ${ }^{34,35}$ In new formulations EDTA is a combination of ethylenediamine (1,2-diaminoethane), sodium cyanide and formaldehyde. ${ }^{35}$ The result of EDTA reaction with calcium ions is soluble calcium chelates. EDTA demineralizes dentine with a depth of 20-30 $\mu \mathrm{m}$ in 5 minutes. ${ }^{36}$

Wu et al. ${ }^{37}$ showed that the $17 \%$ EDTA was notably more powerful than $20 \%$ citric acid, BioPure MTAD and smear clear in removing the smear layer. According to another study, orthophosphoric acid had higher surgical smear layer removing ability with lesser action time than EDTA. ${ }^{38}$

Prado et al. ${ }^{39}$ revealed that phosphoric acid was efficient enough to be comparable to EDTA in removing the smear layer. Another study proved the efficacy of EDTA in removing the smear layer. ${ }^{40}$ According to Caron et al., ${ }^{41}$ the sonic and ultrasonic activation of $17 \%$ EDTA $/ 3 \% \mathrm{NaOCl}$ combination removed the smear layer more efficiently.

Another study which used a scanning electron microscope (SEM) showed that using $\mathrm{NaOCl}$ gel along with EDTA is as efficient as $\mathrm{NaOCl}$ solution in removing the smear layer in three parts of the root canal walls. ${ }^{42}$ In another SEM study, Mello et al. ${ }^{43}$ indicated that the rinsing process with $5 \mathrm{~mL}$ of EDTA continuously for 3 minutes can remove the smear layer from root canal walls effectively. Another study showed that EndoActivator could not enhance the smear layer ability of $\mathrm{NaOCl} /$ EDTA. ${ }^{44}$

Two studies proved the efficacy of EDTA in removing the smear layer. ${ }^{45,46}$ Atomic absorption spectroscopy and SEM results. ${ }^{47}$ indicated that $15 \%$ EDTA was the optimum concentration of calcium ions compared to the other chelating agents and the most effective smear layer removing ability. A study presented that a 1-minute ultrasonic activation of EDTA causes effective smear layer and debris removal of the canal apex. ${ }^{48}$

Saito et al. ${ }^{49}$ showed that an increase in irrigation time with 17\% EDTA from 30 seconds to 1 minute make smear layer removal more efficient after root canal instrumentation. According to another study, application of a combination of EDTA and $\mathrm{NaOCl}$ irrigants, for 1, 3 and 5 minutes showed similar smear removing in the canal walls of straight roots. ${ }^{50}$ Sen et al..$^{51}$ showed no significant difference between different concentrations of EDTA $(15 \%$, $10 \%, 5 \%$, and $1 \%$ ) in the smear layer removal ability.

Perez and Rouqueyrol-Pourcel ${ }^{52}$ showed similar smear layer removing the ability for one minute $15 \%$ EDTA irrigation and three minutes irrigation with $8 \%$ EDTA during root canal provision.

Another study revealed that 3-minute irrigation with EDTA compared to 15 minutes had statistically significantly better results. Furthermore, there were no significant differences for the 3-time intervals of irrigation with EDTA-T. ${ }^{53}$

Adiguzel et al. ${ }^{54}$ indicated that the Self-adjusting File operation with continuously irrigating with EDTA resulted in root canal walls that were free of smear layer in $85 \%, 60 \%$, and $50 \%$ and of debris in $95 \%, 90 \%$, and $85 \%$ of the coronal, middle, and apical thirds of the root canals, respectively.

\section{Maleic Acid}

Maleic acid $\left(\mathrm{C}_{4} \mathrm{H}_{4} \mathrm{O}_{4}\right)$ is a dicarboxylic organic acid that is the trans-isomer of butenedioic acid and cis-isomer of fumaric acid. It is mainly the precursor of fumaric acid, 
and compared to its parent maleic anhydride has more uses. $^{55}$

Maleic acid possesses smear layer removal ability as an acid etchant in restorative dentistry. ${ }^{56}$ Prabhu et $a .^{56}$ got to the result that, using maleic acid at the concentrations than $7 \%$, damaged the intertubular dentin. Ballal et al. ${ }^{57}$ reported that $7 \%$ of maleic acid was a more powerful smear layer removing irrigant than $17 \%$ EDTA in the third part of the root canal apex. Ballal et al. ${ }^{58}$ demonstrated that maleic acid had a similar effect to EDTA in reducing the microhardness of root dentin but enhanced the surface roughness significantly more than EDTA. Furthermore, maleic acid eradicates E. faecalis biofilms when used at a concentration of $0.88 \%$ after 30 seconds and $0.11 \%$ after 2 minutes of contact time. It can eradicate the biofilms at 30 seconds, 1 minute and two minutes in combination with $0.2 \%$ cetrimide. ${ }^{59}$

Final irrigation by $7 \%$ maleic acid can improve the post-obturation apical seal in comparison with $17 \%$ EDTA and has minimal tissue-dissolution capacity in comparison with $\mathrm{NaOCl}{ }^{60,61}$

Ballal et al. ${ }^{62}$ indicated maleic acid's demineralization of the root dentine by energy dispersive spectrometer, with the highest calcium and phosphorus extracted during the first 5 minutes, in comparison with EDTA.

\section{Citric Acid}

Citric acid is an organic weak acid, and a white crystalline powder when at room temperature. There are two forms of citric acid available, monohydrous and anhydrous (water-free). The monohydrous form crystallizes from cold water, whereas the anhydrous forms when citric acid is crystallized in cold water. In the temperatures above $78^{\circ} \mathrm{C}$, the two forms are convertible to each other. ${ }^{63}$

It can be used as an irrigation agent in the root canal to remove the smear layer. ${ }^{64}$ Concentrations ranging from 1 to $50 \%$ have been used. ${ }^{65}$ According to a study, among the concentrations, $10 \%$ of citric acid was more efficient in the smear layer removal from apical root-end cavities than ultrasound. ${ }^{66}$ Another study made a comparison between the antibacterial and chelating features of citric acid and EDTA. The solubility of dentine-resin combined powder was higher in $0.5,1$, and $2 \mathrm{M}$ citric acid concentrations than in a $0.5 \mathrm{M}$ EDTA solution. Citric acid solution possessed antibacterial effects for all 12 root canal bacteria. ${ }^{67}$

However, Liolios et al. ${ }^{68}$ reported better ability in removing the smear layer by commercial EDTA preparations than $50 \%$ citric acid. and two other studies reported either minor or no difference in smear layer removal with $15 \%$ EDTA and citric acid. ${ }^{69,70}$ In a recent study, Machado-Silveiro et al. ${ }^{71}$ measured the demineralization capability of $10 \%$ sodium citrate, $1 \%$ and $10 \%$ citric acid, and 17\% EDTA during immersions of 5,10 , and 15 minutes on root canal dentin which showed the $10 \%$ citric acid as the best efficient agent among the others. Takeda et al. ${ }^{72}$ conducted an ex vivo study on the smear layer removal ability of two kinds of laser and three endodontic irrigants in the apical and middle thirds of root canals. Six percent phosphoric acid, $17 \%$ EDTA, and 6\% citric acid did not have the ability to remove the smear layer thoroughly from the root canal system. Furthermore, these solutions cause tubular opening through demineralization of the intertubular dentine tubular, which in turn caused them to enlarge. According to a study, citric acid solutions removed the smear layer after $60 \mathrm{~s}$ of application, cleaning the dentin tubules, but also widening and demineralizing inter- and peritubular dentin. ${ }^{73}$

\section{Tannic Acid}

Bitter ${ }^{74}$ reported that $25 \%$ of tannic acid had the efficiency to remove the smear layer. The results of another study were contrary to these findings and demonstrated that tannic acid increased the collagen cross-linking within the underlying dentin matrix and the smear layer, thus increasing organic connections to the tubules. ${ }^{75}$

Takahashi et al. ${ }^{76}$ performed a study using scanning electron microscopy and explained that an application of $2 \%$ tannic acid for 60 seconds or $5 \%$ tannic acid for 15,30 , or 60 seconds efficiently removed the smear layer and left the dentinal tubules occluded. Duration of 15 seconds treatment with $40 \%$ phosphoric acid exposed many dentinal tubules and opened their orifices.

\section{Polyacrylic Acid}

Polyacrylic acid (Fuji II liquid and Durelon liquid) at 40\% concentration was reported as a very effective smear layer removing agent. In order to achieve the patency, the acid exposure duration should be lower than 30 seconds according to the studies guide. ${ }^{77}$

\section{Derivatives of Oxine (8-hydroxyquinoline)}

Dequalinium compounds have been used against bacterial and fungal infections widely. Bis-dequaliniumacetate (BDA) has been shown to have the ability of removing the smear layer throughout the canal, even in the apical third. ${ }^{78,79}$ The low surface tension of the BDA helps its penetration into spaces that instruments cannot have access. ${ }^{78}$

According to a study, $5.25 \% \mathrm{NaOCl}$ and Salvizol (a commercial brand of $0.5 \%$ BDA) had comparable efficiencies in removing organic debris; however, only Salvizol was able to open dentinal tubules. ${ }^{80}$ In comparison 
with REDTA, another study declared that Salvizol was less effective at opening dentinal tubules. ${ }^{81}$

\section{HEBP}

1-bisphosphonate, 1-hydroxyethylidene-1or etidronic acid (HEBP) is a chelator that is usable in combination with sodium hypochlorite $(\mathrm{NaOCl})$ keeping its proteolytic or antimicrobial properties intact. ${ }^{82}$ However, the decalcifying property of HEBP is weak compared to EDTA, and thus its use as an only final rinse is limited. Therefore, a mixture of $\mathrm{HEBP}$ and $\mathrm{NaCl}$ is recommended for a complete root canal irrigation. As this solution has a tendency toward $\mathrm{NaOCl}$ production in sodium hypochlorite-hypochlorous acid equilibrium, it has better tissue dissolution capacity than hypochlorous acid $^{83}$ and it has lower cytotoxicity. ${ }^{84}$ In addition, $\mathrm{NaOCl}$ and HEBP mixture has been proposed to optimize the bonding by Resilon/Epiphany root fillings. ${ }^{85}$

Due to calcium hypochlorite adaptation of HEBP, it is used in pool water disinfection as $\mathrm{Ca}(\mathrm{OCl})_{2}$ tablets are used in swimming pools. The HEBP prevents stain formation from inorganic compounds at the water line. It also prevents the accumulation of dentin debris in the root canal during instrumentation. ${ }^{86}$

\section{QMiX}

QMiX is one of the recently introduced mixtures for irrigating the root canal. It was recommended to be used at the end of instrumentation after $\mathrm{NaOCl}$ irrigation. It contains CHX, EDTA, and a detergent, coming as a ready-to-use clear solution. As mentioned above, QMiX usage is limited to the final rinse. Although no precipitate has been described in QMiX and $\mathrm{NaOCl}$ mixture, saline rinse for $\mathrm{NaOCl}$ should be conducted whenever sodium hypochlorite is used throughout the cleaning and shaping processes to prevent the PCA formation. ${ }^{87-89}$

Stojicic et al. ${ }^{87}$ performed a study using scanning electron microscopy and resulted that Q-Mix removed the smear layer similar to the EDTA. Another study represented that QMiX had similar smear layer removing ability as $17 \%$ EDTA after the application of $5.25 \% \mathrm{NaOCl}$ as the initial rinse. ${ }^{88}$

\section{SmearClear}

SmearClear (Orange, Sybron Endo, CA) is a product introduced for removing the smear layer. It is a $17 \%$ EDTA solution including an anionic and cationic (cetrimide) surfactant. There were no significant differences shown between 17\% EDTA, SmearClear, and 10\% citric acid regarding their smear layer removal ability. ${ }^{90}$

Da Silva et al. ${ }^{91}$ represented that SmearClear ability to remove the smear layer from the root canals of permanent teeth was similar to $14.3 \%$ EDTA. Another study got to the result that there was no significant difference between SmearClear and EDTA in the process of removing the smear layer from the root canals of primary teeth. ${ }^{92} \mathrm{On}$ the other hand, Wu et al. ${ }^{93}$ indicated that $17 \%$ EDTA was more efficient than that of SmearClear, whilst another study demonstrated that the efficacy of SmearClear on E. faecalis biofilms was significantly less than $1 \%$ and $6 \%$ $\mathrm{NaOCl}{ }^{94}$

\section{Authors Perspective}

The smear layer removal ability of MTAD is superior and faster than EDTA. Tetraclean is similarly composed of an acid, an antibiotic, and a detergent. The presence of doxycycline is believed to help the smear layer removal ability of these irrigants. Antibiotics such as tetracycline had similar smear layer removal ability as even citric acid. EDTA is an amino acid with a chelating ability that sequestrates metal ions. Some believed EDTA smear layer removing ability is better than MTAD, tetraclean, SmearClear, and $20 \%$ citric acid which is controversial in case of comparison between MTAD and EDTA. Phosphoric acid is efficient enough to be comparable to EDTA in removing the smear layer. Maleic acid is an organic compound with acid etching smear layer removal. Its ability seems to be similar or even better than EDTA. Citric acid as another organic acid is believed to be used as smear removing agent. HEBP is another chelating agent that can be used in combination with $\mathrm{NaOCl}$; however, HEBP is a weak decalcifying agent compared to EDTA and hence cannot be applied as a mere final rinse. QMiX is a combination of CHX, EDTA, and detergent and should be used at final rinse. It is believed that QMiX is as efficient as EDTA. SmearClear is a 17\% EDTA solution including an anionic and cationic (cetrimide) surfactant. The ability of QMiX is similar to EDTA.

\section{CONCLUSION}

Different canal irrigation agents with different clinical significance and usage have been proposed. These ranges from combinatory solutions to organic acids and even some of the antibiotics such as doxycycline. MTAD, EDTA, QMiX, SmearClear seems to have a similar smear layer removing abilities. However, many believe EDTA is more effective than MTAD. Contrary, some proposed that MTAD is more efficient than EDTA. QMiX and SmearClear should be used at final rinse. Still, controversies remained in this topic.

\section{REFERENCES}

1. Basrani B, Haapasalo M. Update on endodontic irrigation solutions. Endod Topics 2012;27:74-102. 
2. Violich DR, Chandler NP. The smear layer in endodontics - a review. Int Endod J 2010;43:2-15.

3. Cameron JA. The use of ultrasound for the removal of the smear layer. The effect of sodium hypochlorite concentration; SEM study. Aust Dent J 1988;33:193-200.

4. McComb D, Smith DC. A preliminary scanning electron microscopic study of root canals after endodontic procedures. J Endod 1975;1:238-242.

5. Mader CL, Baumgartner JC, Peters DD. Scanning electron microscopic investigation of the smeared layer on root canal walls. J Endod 1984;10:477-483.

6. Cengiz T, Aktener BO, Piskin B. Effect of dentinal tubule orientation on the removal of smear layer by root canal irrigants. A scanning electron microscopic study. Int Endod J 1990;23:163-171.

7. Ahlquist $\mathrm{M}$, Henningsson $\mathrm{O}$, Hultenby $\mathrm{K}$, et al. The effectiveness of manual and rotary techniques in the cleaning of root canals: a scanning electron microscopy study. Int Endod J 2001;34:533-537.

8. Bertrand MF, Pizzardini P, Muller M, et al. The removal of the smear layer using the Quantec system. A study using the scanning electron microscope. Int Endod J 1999;32:217-224.

9. Perez F, Calas P, Rochd T. Effect of dentin treatment on in vitro root tubule bacterial invasion. Oral Surg Oral Med Oral Pathol Oral Radiol Endod 1996;82:446-451.

10. Ørstavik D, Haapasalo M. Disinfection by endodontic irrigants and dressings of experimentally infected dentinal tubules. Endod Dent Traumatol 1990;6:142-149.

11. Bystro"m A, Sundqvist G. The antibacterial action of sodium hypochlorite and EDTA in 60 cases of endodontic therapy. Int Endod J 1985;18:35-40.

12. Tidmarsh BG. Acid-cleansed and resin-sealed root canals. J Endod 1978;4:117-121.

13. White R, Goldman M, Peck S-L. The influence of the smeared layer upon dentinal tubule penetration by plastic filling materials. J Endod 1984;10:558-562.

14. Pitt Ford TR, Roberts GJ. Tissue response to glass ionomer retrograde root fillings. Int Endod J 1990;23:233-238.

15. Saleh IM, Ruyter IE, Haapasalo MP, et al. Adhesion of endodontic sealers: scanning electron microscopy and energy dispersive spectroscopy. J Endod 2003;29:595-601.

16. Kokkas AB, Boutsioukis ACh, Vassiliadis LP, et al. The influence of the smear layer on dentinal tubule penetration depth by three different root canal sealers: an in vitro study. J Endod 2004;30:100-2.

17. Gettleman BH, Messer HH, ElDeeb ME. Adhesion of sealer cements to dentin with and without the smear layer. J Endod 1991;17:15-20.

18. Torabinejad M, Khademi AA, Babagoli J, et al. A new solution for the removal of the smear layer. J Endod 2003;29: 170-175.

19. Torabinejad M, Shabahang S, Aprecio R, et al. The antimicrobial effect of MTAD: An in vitro investigation. J Endod 2003;29:400-403.

20. Lotfi M, Vosoughhosseini S, Saghiri MA, et al. Effect of MTAD as a final rinse on removal of smear layer in ten-minute preparation time. J Endod 2012;38:1391-1394.

21. Tay FR, Pashley D, Loushine RJ, et al. Ultrastructure of smear layer-covered intraradicular dentin after irrigation with BioPure MTAD. J Endod 2006;32:218-221.

22. De-Deus G, Reis C, Fidel S, et al. Dentin demineralization when subjected to BioPure MTAD: a longitudinal and quan- titative assessment. J Endod 2007;33:1364-1368.

23. Giardino L, Pecora G, Ambu E, et al. A new irrigant in the treatment of apical periodontitis: from research to clinic. 12th Biennial Congress European Society of Endodontology, Dublin, September, 2005;15-17.

24. Giardino L, Ambu E, Becce C, et al. Surface tension comparison of four common root canal irrigants and two new irrigants containing antibiotic. J Endod 2006;32:1091-1093.

25. Poggio C, Dagna A, Colombo M, et al. Decalcifying effect of different ethylenediaminetetraacetic acid irrigating solutions and Tetraclean on root canal dentine. J Endod 2012;38:12391243

26. Barkhordar RA, Watanabe LG, Marshall GW, et al. Removal of intracanal smear by doxycycline in vitro. Oral Surg Oral Med Oral Pathol Oral Radiol Endod 1997;84:420-423.

27. Pierce A, Lindskog S. The effect of an antibiotic/corticosteroid paste on inflammatory root resorption in vivo. Oral Surg Oral Med Oral Pathol Oral Radiol Endod 1987;64:216-220.

28. Pierce A, Heithersay G, Lindskog S. Evidence for direct inhibition of dentinoclasts by a corticosteroid / antibiotic endodontic paste. Endod Dent Traumatol 1988;4:44-45.

29. Bryson E, Levin L, Banchs F, et al. Effect of immediate intracanal placement of Ledermix paste on healing of replanted dog teeth after extended dry times. Dent Traumatol 2002;18:316321.

30. Haznedaroğlu F, Ersev $\mathrm{H}$. Tetracycline $\mathrm{HCl}$ solution as a root canal irrigant. J Endod 2001;27:738-740

31. Barkhordar RA, Russell T. Effect of doxycycline on the apical seal of the retrograde filling materials. J Calif Dent Assoc 1998;26:842-845.

32. Molander A, Dahlen G. Evaluation of the antibacterial potential of tetracycline or erythromycin mixed with calcium hydroxide as intracanal dressing against E. faecalis in vivo. Oral Surg Oral Med Oral Pathol Oral Radiol Endod 2003;96:744-750.

33. Holleman AF, Wiberg E. Inorganic Chemistry. Academic Press: 2001; San Diego, ISBN 0-12-352651-5.

34. Furia T. EDTA in Foods - A technical review. Food Technol 1964;18:1874-1882.

35. Harris DC. Quantitative Chemical Analysis. 7th ed., 2007; W. H. Freeman and Compagny, New York.

36. Hulsmann M, Heckendorff M, Lennon A. Chelating agents in root canal treatment: mode of action and indications for their use. Int Endod J 2003;36:810-830.

37. Wu L, Mu Y, Deng X, et al. Comparison of the effect of four decalcifying agents combined with $60^{\circ} \mathrm{C} 3 \%$ sodium hypochlorite on smear layer removal. J Endod 2012;38:381-384.

38. Fabiani C, Franco V, Covello F, et al. Removal of surgical smear layer. J Endod 2011;37:836-838.

39. Prado M, Gusman H, Gomes BP, et al. Scanning electron microscopic investigation of the effectiveness of phosphoric acid in smear layer removal when compared with EDTA and citric acid. J Endod 2011;37:255-258.

40. Rödig T, Döllmann S, Konietschke F, et al. Effectiveness of different irrigant agitation techniques on debris and smear layer removal in curved root canals: a scanning electron microscopy study. J Endod 2010;36:1983-1987.

41. Caron G, Nham K, Bronnec F, et al. Effectiveness of different final irrigant activation protocols on smear layer removal in curved canals. J Endod 2010;36:1361-1366.

42. Zand V, Lotfi M, Rahimi S, et al. A comparative scanning electron microscopic investigation of the smear layer after 
the use of sodium hypochlorite gel and solution forms as root canal irrigants. J Endod 2010;36:1234-1237.

43. Mello I, Kammerer BA, Yoshimoto D, et al. Influence of final rinse technique on ability of ethylenediaminetetraacetic acid of removing smear layer. J Endod 2010;36:512-514.

44. Uroz-Torres D, González-Rodríguez MP, Ferrer-Luque CM. Effectiveness of the EndoActivator System in removing the smear layer after root canal instrumentation. J Endod 2010;36:308-311.

45. Mancini M, Armellin E, Casaglia A, et al. A comparative study of smear layer removal and erosion in apical intraradicular dentine with three irrigating solutions: a scanning electron microscopy evaluation. J Endod 2009;35:900-903.

46. da Silva LA, Sanguino AC, Rocha CT, et al. Scanning electron microscopic preliminary study of the efficacy of SmearClear and EDTA for smear layer removal after root canal instrumentation in permanent teeth. J Endod 2008;34:1541-1544.

47. Spanó JC, Silva RG, Guedes DF, et al. Atomic absorption spectrometry and scanning electron microscopy evaluation of concentration of calcium ions and smear layer removal with root canal chelators. J Endod 2009;35:727-730.

48. Kuah HG, Lui JN, Tseng PS, et al. The effect of EDTA with and without ultrasonics on removal of the smear layer. J Endod 2009;35:393-396.

49. Saito K, Webb TD, Imamura GM, et al. Effect of shortened irrigation times with $17 \%$ ethylene diamine tetra-acetic acid on smear layer removal after rotary canal instrumentation. J Endod 2008;34:1011-1014.

50. Teixeira CS, Felippe MC, Felippe WT. The effect of application time of EDTA and $\mathrm{NaOCl}$ on intracanal smear layer removal: an SEM analysis. Int Endod J 2005;38:285-290.

51. Sen BH, Ertürk O, Pişkin B. The effect of different concentrations of EDTA on instrumented root canal walls. Oral Surg Oral Med Oral Pathol Oral Radiol Endod 2009;108:622-627.

52. Perez F, Rouqueyrol-Pourcel N. Effect of a low-concentration EDTA solution on root canal walls: a scanning electron microscopic study. Oral Surg Oral Med Oral Pathol Oral Radiol Endod 2005;99:383-387.

53. Scelza MF, Teixeira AM, Scelza P. Decalcifying effect of EDTA-T, $10 \%$ citric acid, and 17\% EDTA on root canal dentine. Oral Surg Oral Med Oral Pathol Oral Radiol Endod 2003;95:234-236.

54. Adigüzel O, Yiğit-Özer S, Kaya S, et al. Effectiveness of ethylenediaminetetraacetic acid (EDTA) and MTAD on debris and smear layer removal using a self-adjusting file. Oral Surg Oral Med Oral Pathol Oral Radiol Endod 2011;112:803-808.

55. James MN, Williams GJ. A Refinement of the Crystal Structure of Maleic Acid. Acta Crystallograph 1974;B30:1249-1275.

56. Prabhu SG, Rahim N, Bhat KS, et al. Comparison of removal of endodontic smear layer using sodium hypochlorite, EDTA and different concentrations of maleic acid-a SEM study. Endodontol 2003;15:20-25.

57. Ballal NV, Kandian S, Mala K, et al. Comparison of the efficacy of maleic acid and ethylenediaminetetraacetic acid in smear layer removal from instrumented human root canal: a scanning electron microscopic study. J Endod 2009;35:1573-1576.

58. Ballal NV, Mala K, Bhat KS. Evaluation of the effect of maleic acid and ethylenediaminetetraacetic acid on the microhardness and surface roughness of human root canal dentin. J Endod 2010;36:1385-1388.

59. Ferrer-Luque CM, Arias-Moliz MT, González-Rodríguez MP, et al. Antimicrobial activity of maleic acid and combinations of cetrimide with chelating agents against Enterococcus faecalis biofilm. J Endod 2010;36:1673-1675.

60. Ballal NV, Kundabala M, Bhat KS. A comparative evaluation of post-obturation apical seal following intracanal irrigation with maleic acid and EDTA: a dye leakage under vacuum study. Oral Surg Oral Med Oral Pathol Oral Radiol Endod 2010;109:e126-130.

61. Ballal NV, Mala K, Bhat KS. Effect of maleic acid and ethylenediaminetetraacetic acid on the dissolution of human pulp tissue--an in vitro study. Int Endod J 2011;44:353-356.

62. Ballal NV, Mala K, Bhat KS. Evaluation of decalcifying effect of maleic acid and EDTA on root canal dentin using energy dispersive spectrometer. Oral Surg Oral Med Oral Pathol Oral Radiol Endod 2011;112:e78-84.

63. Walid LA, Khaled GM, El-Helow ER. Citric acid production by a novel Aspergillus niger isolate: II. Optimization of process parameters through statistical experimental designs. Bioresource Technol 2007;98:3470-3477.

64. Haapasalo M, Endal U, Zandi H, et al. Eradication of endodontic infection by instrumentation and irrigation solutions. Endod Topics 2005;10:77-102.

65. Loel DA. Use of acid cleanser in endodontic therapy. J Am Dent Assoc 1975;90:148-151.

66. Gutmann JL, Saunders WP, Nguyen L, et al. Ultrasonic root-end preparation. Part 1.SEM analysis. Int Endod J 1994;27:318-324.

67. Yamaguchi M, Yoshida K, Suzuki R, et al. Root canal irrigation with citric acid solution. J Endod 1996;22:27-29.

68. Liolios E, Economides N, Parissis-Messimeris S, Boutsioukis A. The effectiveness of three irrigating solutions on root canal cleaning after hand and mechanical preparation. Int Endod J 1997;30:51-57.

69. Di Lenarda R, Cadenaro M, Sbaizero O. Effectiveness of 1 mol L-1 citric acid and 15\% EDTA irrigation on smear layer removal. Int Endod J 2000;33:46-52.

70. Scelza MF, Teixeira AM, Scelza P. Decalcifying effect of EDTA-T, $10 \%$ citric acid, and 17\% EDTA on root canal dentine. Oral Surg Oral Med Oral Pathol Oral Radiol Endod 2003;95:234-236.

71. Machado-Silveiro LF, Gonzalez-Lopez S, Gonzalez-Rodriguez MP. Decalcification of root canal dentine by citric acid, EDTA and sodium citrate. Int Endod J 2004;37:365-369.

72. Takeda FH, Harashima T, Kimura Y, et al. A comparative study of the removal of smear layer by three endodontic irrigants and two types of laser. Int Endod J 1999;32: 32-39.

73. Reis C, De-Deus G, Leal F, Azevedo E, et al. Strong effect on dentin after the use of high concentrations of citric acid: An assessment with co-site optical microscopy and ESEM. Dent Mater 2008;24:1608-1615.

74. Bitter NC. A $25 \%$ tannic acid solution as a root canal irrigant cleanser: A scanning electron microscope study. Oral Surg Oral Med Oral Pathol 1989;67:333-337.

75. Sabbak SA, Hassanin MB. A scanning electron microscopic study of tooth surface changes induced by tannic acid. J Prosthet Dent 1998;79:169-174.

76. Takahashi H, Okamoto Y, Fujinaka S, Shintani H. A pilot study of exposure of the smear layer to tannic acid solutions. J Prosthet Dent. 1993 Sep;70(3):261-263.

77. Berry EA, von der Lehr WN, Herrin HK. Dentin surface treatments for the removal of the smear layer: an SEM study. J Am Dent Assoc 1987;115:65-67. 
78. Kaufman AY, Binderman I, Tal M, Gedalia I, Peretz G. New chemotherapeutic agent for root canal treatment. Oral Surg Oral Med Oral Pathol 1978;46:283-295.

79. Kaufman AY. The use of dequalinium acetate as a disinfectant and chemotherapeutic agent in endodontics. Oral Surg Oral Med Oral Pathol 1981;51:434-441.

80. Kaufman AY, Greenberg I. Comparative study of the configuration and the cleanliness level of root canals prepared with the aid of sodium hypochlorite and bis-dequaliniumacetate solutions. Oral Surg Oral Med Oral Pathol 1986;62: 191-197.

81. Berg MS, Jacobsen EL, BeGole EA, Remeikis NA. A comparison of five irrigating solutions: A scanning electron microscopic study. J Endod 1986;12:192-197.

82. Zehnder M. Root canal irrigants. Review. J Endod 2006:32:389-398.

83. Christensen CE, McNeal SF, Eleazer P. Effect of lowering the $\mathrm{pH}$ of sodium hypochlorite on dissolving tissue in vitro. J Endod 2008:4:449-452.

84. Aubut V, Pommel L, Verhille B, et al. Biological properties of a neutralized $2.5 \%$ sodium hypochlorite solution. Oral Surg Oral Med Oral Pathol Oral Radiol Endod 2010;109:e120-e125.

85. De-Deus G, Namen F, Galan J Jr, Zehnder M. Soft chelating irrigation protocol optimizes bonding quality of Resilon/ Epiphany root fillings. J Endod 2008;6:703-705.

86. Paqué F, Rechenberg DK, Zehnder M. Reduction of hardtissue debris accumulation during rotary root canal instrumentation by etidronic acid in a sodium hypochlorite irrigant. J Endod 2012;5:692-695.
87. Stojicic S, Shen Y, Qian W, Johnson B, Haapasalo M. Antibacterial and smear layer removal ability of a novel irrigant, QMiX. Int Endod J 2012;45:363-371.

88. Dai L, Khechen K, Khan S, Gillen B, Loushine BA, Wimmer CE, Gutmann JL, Pashley D, Tay FR. The effects of QMiX, an experimental antibacterial root canal irrigant, on removal of canal wall smear layer and debris. J Endod 2011;7: 80-84.

89. Ma J, Wang Z, Shen Y, Haapasalo M. A new noninvasive model to study the effectiveness of dentin disinfection by using confocal laser scanning microscopy. J Endod 2011;37:1380-1385.

90. Khedmat S, Shokouhinejad N. Comparison of the efficacy of three chelating agents in smear layer removal. J Endod 2008;34:599-602.

91. da Silva LA, Sanguino AC, Rocha CT, Leonardo MR, Silva RA. Scanning electron microscopic preliminary study of the efficacy of SmearClear and EDTA for smear layer removal after root canal instrumentation in permanent teeth. J Endod 2008;34:1541-1544.

92. Nelson-Filho P, Leite Gde A, Fernandes PM, et al. Efficacy of SmearClear and ethylenediaminetetraacetic acid for smear layer removal in primary teeth. J Dent Child (Chic) 2009;76: 74-77.

93. Wu L, Mu Y, Deng X, et al. Comparison of the effect of four decalcifying agents combined with $60^{\circ} \mathrm{C} 3 \%$ sodium hypochlorite on smear layer removal. J Endod 2012;38:381-384.

94. Dunavant TR, Regan JD, Glickman GN, et al. Comparative evaluation of endodontic irrigants against Enterococcus faecalis biofilms. J Endod 2006;32: 527-531. 